BIS WORKING PAPERS

No 89 - August 2000

\title{
FORECAST-BASED MONETARY POLICY
}

by

Jeffery D Amato and

Thomas Laubach

BANK FOR INTERNATIONAL SETTLEMENTS

Monetary and Economic Department

Basel, Switzerland 
BIS Working Papers are written by members of the Monetary and Economic Department of the Bank for International Settlements, and from time to time by other economists, and are published by the Bank. The papers are on subjects of topical interest and are technical in character. The views expressed in them are those of their authors and not necessarily the views of the BIS.

Copies of publications are available from:

Bank for International Settlements

Information, Press \& Library Services

CH-4002 Basel, Switzerland

Fax: +41 61 / 2809100 and +4161/2808100

This publication is available on the BIS website (www.bis.org).

(C) Bank for International Settlements 2000.

All rights reserved. Brief excerpts may be reproduced or translated provided the source is stated. 


\title{
BIS WORKING PAPERS
}

No 89 - August 2000

\section{FORECAST-BASED MONETARY POLICY}

\author{
by
}

\author{
Jeffery D Amato and \\ Thomas Laubach*
}

\begin{abstract}
This article analyses the welfare consequences of delegating to the central bank the task of minimising deviations of forecasts of goal variables from their target values. The delegated objectives considered in this article are motivated by the observation that central banks oftentimes operate under objectives which do not necessarily represent society's preferences. The analysis is performed using an estimated model of optimising households and firms that generates tradeoffs between stabilising wage and price inflation and the output gap. We find that when the central bank's objective is defined solely in terms of price inflation, it is welfare optimal to stabilise only those fluctuations in price inflation that are forecastable at least five quarters ahead. On the other hand, when the central bank's objective involves both wage and price inflation stabilisation, the central bank should stabilise all fluctuations in these variables, not just those forecastable at some horizon.
\end{abstract}

* E-mail: jeffery.amato@ bis.org; Thomas Laubach, Board of Governors of the Federal Reserve System, tlaubach@ frb.gov. This is a substantially revised version of an earlier paper that appeared as Federal Reserve Bank of Kansas City Working Paper No 99-10, October 1999. We gratefully acknowledge many helpful discussions with Michael Woodford, as well as comments from Mark Gertler, Peter Ireland, Julio Rotemberg, Argia Sbordone, John Taylor and seminar participants at the Bank for International Settlements, Deutsche Bundesbank, the European Central Bank, Sveriges Riksbank and the Austrian National Bank. All remaining errors are ours. The views expressed herein are those of the authors and do not necessarily reflect those of the Bank for International Settlements, the Board of Governors of the Federal Reserve System, or the staff of either institution. 



\section{Contents}

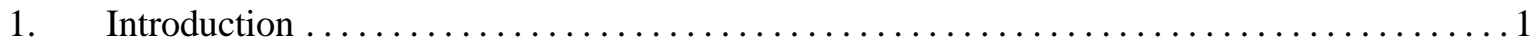

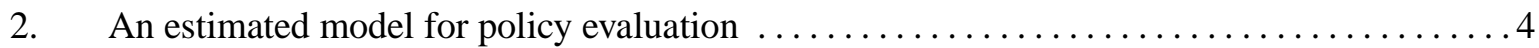

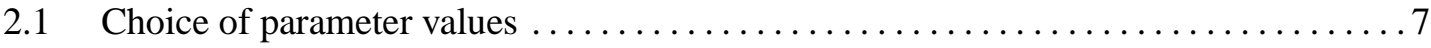

3. Alternative objectives for monetary policy $\ldots \ldots \ldots \ldots \ldots \ldots \ldots \ldots \ldots \ldots \ldots \ldots \ldots$

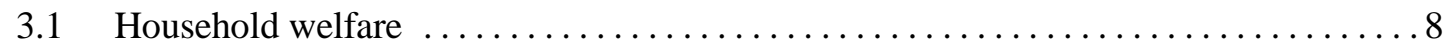

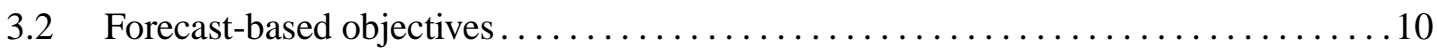

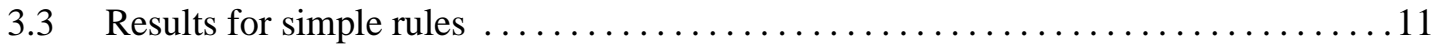

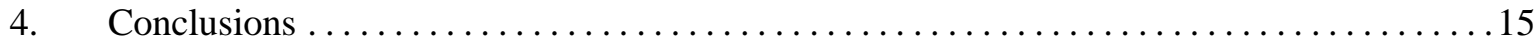

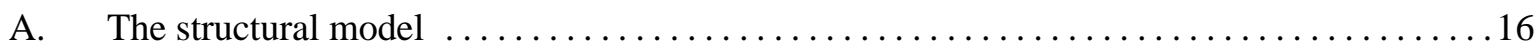

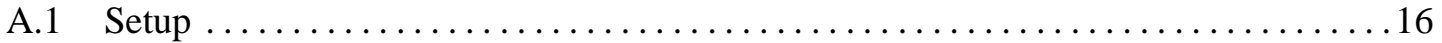

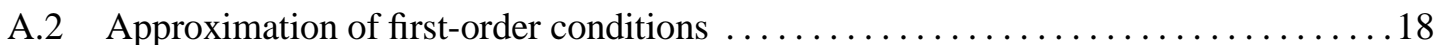

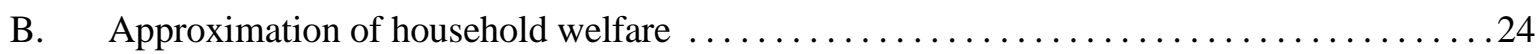

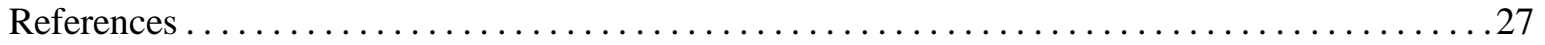





\section{Introduction}

Forecasts of goal variables such as output and inflation play an important role in the policy process of many central banks. A common rationale for the use of forecasts in decisions about interest rates is that monetary policy affects those goal variables only with substantial lags. Absent some intermediate target variable which would largely capture the effect of the current stance of monetary policy on the future values of those goal variables, it may be optimal for the central bank to set its instrument such that the forecast of the goal variables conditional on current information and the current interest rate coincides with one's targets for the goal variables.

A second rationale for the use of forecasts in monetary policy decisions has been suggested by the experience of countries that use inflation targets as a monetary policy strategy. In inflation-targeting countries, the central bank is charged with achieving and maintaining a specific level of inflation in some price index. There is no equivalent numerical goal for any other economic variable that monetary policy should achieve. It has been argued that, if the central bank would attempt to maintain inflation period by period at exactly the target, the instrument movements necessary for doing so would impart a large amount of undesirable volatility to other variables, such as output. Goodhart (1998) suggests that, by adjusting the instrument such as to stabilise the forecast of inflation at some appropriate horizon around the target level, the central bank can largely succeed in stabilising actual inflation, while avoiding destabilising effects on output.

In this paper, we study the consequences of using forecasts as a guide for monetary policy. Forecastbased monetary policy is modelled as the delegation of an objective to the central bank defined in terms of deviations of the forecast for some variable at a specific horizon from some target value. In this formulation, inflation targeting, for example, is interpreted as the central bank having to set interest rates such as to minimise deviations of inflation from target that are expected to occur beyond a certain horizon. If this horizon is short, the central bank is charged with minimising all deviations of inflation from target, whereas a longer horizon implies that only deviations forecastable some time in the future are to be minimised. Because our model is based on optimising behaviour of households, the representative household's welfare provides a natural benchmark for the evaluation of alternative objectives delegated to the central bank. We ask whether welfare benefits result from the delegation of such objectives with forecast horizons beyond any assumed control lags, in particular when there exist variability tradeoffs among economic variables such as wage and price inflation and the output gap.

Our analysis is motivated by the observation that in practice the objectives delegated to central banks are not necessarily reflecting some judgment about the precise form of the preferences of society. For 
example, as mentioned earlier, in inflation targeting countries there exists no target for output equivalent to the target for inflation delegated to the central bank. Yet, the intention of delegating an objective defined solely in terms of inflation is presumably not to make the central bank oblivious to the output consequences of its decisions. Nor do we assume, as in a strand of literature beginning with Rogoff (1985), that the reason for delegating an objective different than the representative household's welfare to the central bank is the central bank's inability to act under commitment. On the contrary, we assume that the central bank is able to commit itself to setting policy such as to achieve the objective delegated to it.

One possible rationale for such delegation might be that delegation of a more complex objective, such as one involving some definition of the output gap, leads to problems in holding the central bank accountable for its performance, if only because the output gap is measured with great uncertainty. A complementary rationale for instructing the central bank to focus only on inflation, and only on the component of inflation which is forecastable sufficiently far in advance, is that this forecastable component may be interpreted as a measure of underlying or trend inflation. Arguably, the central bank should be held responsible primarily for developments in underlying inflation, and not necessarily for high-frequency fluctuations in inflation which it is unable to control. The delegated objectives analysed in this study formalise the idea that the central bank is being evaluated based on its forecasts, as opposed to realisations of variables.

To analyse the welfare properties of various objectives for monetary policy, we use a model in which households maximise their utility by choosing consumption and renegotiating wages in a staggered fashion, and firms engage in staggered price setting for their products. Because we wish to evaluate economic performance under alternative policy rules, not only is it important to spell out the model in terms of individual optimising behaviour, but the model should also perform well in explaining the historical data. In Amato and Laubach (1999) we estimate the model with sticky prices and wages using methods developed in Rotemberg and Woodford (1997). The estimated model is used for performing the simulations reported in this study.

Our findings are twofold. First, a policy that aims solely at stabilising price inflation comes fairly close in terms of welfare to the welfare-optimal policy. In this case, monetary policy should aim at stabilising only fluctuations in inflation that are forecastable five quarters ahead, as opposed to stabilising all fluctuations. A policy that stabilises the conditional expectation of inflation five quarters ahead around target reduces welfare losses compared to a policy that aims at stabilising current inflation. The higher unconditional variance of inflation under a policy that stabilises expected inflation five quarters ahead, 
compared to a policy of current inflation stabilisation, is more than offset by a reduction in the variance of wage inflation. Second, however, a policy aimed at stabilising fluctuations in both price and wage inflation dominates a policy of stabilising just price inflation. Stabilising merely fluctuations in price and wage inflation that are forecastable at some horizon results in sizeable welfare losses. Hence, if an objective in terms of more than one variable is to be delegated to the central bank, stabilising forecasts is inferior to stabilising all fluctuations of those variables.

The results of this study contribute to a growing literature on "inflation forecast targeting". ${ }^{1}$ Svensson (1997) considers the implications for optimal monetary policy when inflation can be controlled by the central bank only with some time lag (the first of the two rationales mentioned above). In a model with backward-looking private agents, the optimal policy when society cares only about inflation variability is to set the central bank's instrument such that the inflation forecast at the horizon of the control lag equals the target. When society cares about both inflation and output variability, any discrepancy between the inflation forecast and the target is reduced more gradually the larger the relative weight on output stabilisation. Svensson and Woodford (1999) characterise optimal policy in the presence of control lags in a model with a forward-looking private sector. Again optimal policy can be expressed in the form of a condition for the path of the central bank's inflation forecasts. Both of these articles provide a rationale for the use of forecasts at the horizon of the control lag, but are not concerned with the use of forecasts at a horizon longer than this control lag. By contrast, in the practice of many central banks, forecasts well beyond the shortest horizon at which monetary policy can significantly affect the goal variables seem to play a key role.

The contributions by Batini and Haldane (1999) and Levin et al (1999) consider one particular formulation of the issue of forecast horizon. Batini and Haldane consider the use of feedback rules in which the central bank sets the short-term interest rate in proportion to the discrepancy between its inflation forecast at a certain horizon and the inflation target. In a largely backward-looking model calibrated to the UK economy, they find that forecast horizons between 4 and 7 quarters minimise a weighted average of inflation and output variability. Levin et al compare the performance of interest rate rules such as Batini and Haldane's to conventional feedback rules (similar to Taylor's) within four different models, and find that advantages of forecast-based rules over conventional ones are minor at best, and nonrobust across model specifications. Moreover, once forward-looking behaviour of the private sector becomes more important, the use of forecast-based rules oftentimes causes indeterminacy of rational expectations equilibrium. Because the model used in this article emphasises forward-looking

\footnotetext{
1 Our analysis is concerned with the role that the central bank's own forecasts play in setting monetary policy. Accordingly, we are not analysing any problems associated with the central bank's use of outside forecasts, as considered in Bernanke and Woodford (1997).
} 
behaviour of the private sector, this drawback of modelling the use of forecasts via a specific form of feedback rule is particularly pertinent.

Batini and Nelson (2000) define the concept of the optimal policy horizon as the welfare-optimal horizon within which inflation should be returned to its target level following a shock, as distinct from the optimal feedback horizon, which is the optimal horizon according to the Batini-Haldane definition. The concept of forecast horizon emphasised in this article differs from Batini-Nelson's optimal policy horizon in that their concept is not cast in the operational form of an objective delegated to the central bank. Depending on the importance of forward-looking elements in their models, Batini and Nelson find optimal policy horizons between 9 and 18 quarters.

The contribution most closely related to this study is that of Smets (2000). Smets interprets the objective of price stability delegated to the central bank as a constraint that at each point in time the central bank's instrument has to be set such that the expectation of inflation (or the price level) at some specified future date is on target. Only subject to this constraint is the central bank free to pursue secondary objectives such as minimising output gap or interest rate variability. Depending on the precise form of the social loss function and the objective delegated to the central bank, Smets finds in a model calibrated to the Euro area that the optimal policy horizon is between 3 and 8 years. His work is similar to ours in that monetary policy is conducted under a delegated objective different from the social loss function, and the issue of interest is the optimal form of the delegated objective. However, presenting the primacy of price stability as a constraint on the central bank has the implication that the central bank is forced to achieve its primary goal under any circumstances, whereas our formulation of objectives allows for a more gradual tradeoff among objectives.

The remainder of the paper is structured as follows. In section 2, we briefly present the model and the estimated parameters. ${ }^{2}$ In section 3, we present the objective that characterises individual welfare and introduce the forecast-based objectives. We then compare economic performance under the different interest-rate policies that are optimal for the various objectives. Section 4 concludes. The model's structural equations and the welfare objective, presented in sections 2 and 3, are derived in two appendices.

\section{An estimated model for policy evaluation}

In this section, we describe the model which we use in our policy simulations. The model is a slight variant of the one developed in Erceg et al (2000). It is a model of price inflation, wage inflation and

\footnotetext{
2 The reader is referred to our earlier work for details on the estimation method and results.
} 
output determination in which the real effects of monetary policy are due to imperfect competition and staggered price and wage setting in goods and labour markets. A model with nominal rigidities in both goods and labour markets is interesting for several reasons. First, evidence on staggered wage setting is certainly at least as persuasive as evidence on staggered price setting. Furthermore, as demonstrated in Erceg (1997), staggered wage setting generates a flat marginal cost schedule at the individual firm level, and hence persistent output effects of monetary shocks, without assumptions on the elasticity of labour supply that are in conflict with evidence from micro data.

More directly related to the questions raised in the introduction, Erceg et al (2000) show that the model with staggered price and wage setting generates a tradeoff between the variability of price inflation, wage inflation and the output gap. If there is more than one source of nominal rigidity in the economy, stabilising the price level does not imply stabilising output around the Pareto-optimal level that would obtain in the flexible price and wage case. This is in contrast to the results of, eg, Rotemberg and Woodford (1997), who show that in a model with only one nominal rigidity, complete output gap and inflation stabilisation is feasible, and hence no output-inflation variability tradeoff exists. A model with staggered price and wage setting, therefore, provides a framework in which the validity of Goodhart's suggestion discussed in the introduction can be assessed.

The spending relation that we use is an example of a "forward-looking IS equation" (eg McCallum and Nelson, 1999), which can be derived from the representative household's consumption Euler equation:

$$
\hat{Y}_{t}=-\sigma^{-1} E_{t} \sum_{T=t}^{\infty}\left[\hat{R}_{T}-\pi_{T+1}\right]+\hat{G}_{t}
$$

where $\hat{Y}_{t}$ is $(\log )$ output, $\hat{R}_{t}$ is a one-period nominal interest rate, $\pi_{t}$ is the one-period rate of price inflation and $\hat{G}_{t}$ is a "demand shock". 3 All variables are expressed as percent deviations from their

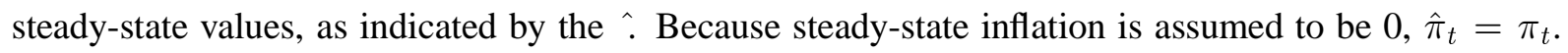
The parameter $\sigma^{-1}$ denotes households' intertemporal elasticity of substitution in consumption.

The assumption for wage and price adjustment we use is a variant of Calvo's (1983) staggered price setting. Each period a fraction $1-\lambda$ of households is chosen at random and independent of their individual histories, and is being offered the opportunity to set a new wage. Hence, from the perspective of an individual household, the wage set in period $t$ applies with probability 1 in period $t$, with probability $\lambda$ it applies in period $t+1$, with probability $\lambda^{2}$ in period $t+2$ and so forth. The (linearised) condition characterising households' optimal choice of wages implies the following law of motion for wage

\footnotetext{
3 The variable $\hat{G}_{t}$ is a composite of government expenditures (assumed to be exogenous) and taste shocks.
} 
inflation:

$$
\pi_{t}^{w}=\kappa^{w}\left(\hat{Y}_{t}-\hat{Y}_{t}^{w}\right)-\delta^{w} \hat{w}_{t}+\beta E_{t} \pi_{t+1}^{w}
$$

where $\pi_{t}^{w}$ is the rate of wage inflation, $\hat{w}_{t}$ is the real wage and $\hat{Y}_{t}^{w}$ the level of output consistent with stable wage inflation. ${ }^{4}$ The coefficient $\kappa^{w}$ describes the elasticity of wage inflation with respect to the gap between actual output $\hat{Y}_{t}$ and $\hat{Y}_{t}^{w}$. Because the coefficient $\delta^{w}$ is positive, positive deviations of the real wage from steady state reduce wage inflation.

Analogous to wage adjustment by households, we assume that firms set prices according to Calvo. This leads to a version of what has been called the New Keynesian Phillips curve by Roberts (1995) and others. Each period a fraction $1-\alpha$ of firms is chosen at random and independent of their individual histories, and is being offered the opportunity to adjust their price. The (linearised) condition characterising firms' price decisions then implies that price inflation develops according to

$$
\pi_{t}=\kappa^{p}\left(\hat{Y}_{t}-\hat{Y}_{t}^{p}\right)+\delta^{p} \hat{w}_{t}+\beta E_{t} \pi_{t+1}
$$

where $\hat{Y}_{t}^{p}$ is the level of output consistent with stable price inflation. The positive coefficient $\delta^{p}$ implies that positive deviations of the real wage from steady state raise price inflation.

The model used in the simulations below is actually slightly different from that represented by equations (1)-(3). Namely, as in Amato and Laubach (1999), we introduce implementation lags in the optimising decisions of households and firms in a way analogous to Rotemberg and Woodford (1997). As shown in these studies, this modification improves the fit of the model to US data. Specifically, we assume that households choose their consumption purchases two periods ahead. ${ }^{5}$ The result is that expectations in (1) are now conditioned on information as of time $t-2$, so that the IS equation becomes

$$
\hat{Y}_{t}=-\sigma^{-1} E_{t-2} \sum_{T=t}^{\infty}\left[\hat{R}_{T}-\pi_{T+1}\right]+\hat{G}_{t}
$$

We also assume that similar delays are involved in implementing wage and price changes. At the end of period $t-1$, a fraction $\gamma^{w}$ of those households who choose a new wage can apply this wage beginning at date $t$, while the remaining fraction $1-\gamma^{w}$ must wait till the beginning of date $t+1$. This leads to a modified equation describing the evolution of wage inflation

$$
\pi_{t}^{w}=\left(1-\psi^{w}\right) E_{t-2} \pi_{t}^{w}+\psi^{w}\left[\kappa^{w}\left(\hat{Y}_{t}-\hat{Y}_{t}^{w}\right)-\delta^{w}\left(\hat{w}_{t}+\nu_{t-1}\right)+\beta E_{t-1} \pi_{t+1}^{w}\right]
$$

4 Specifically, $\hat{Y}_{t}^{w}$ and its analog $\hat{Y}_{t}^{p}$ in (3) denote percent deviations from steady state of the levels of output consistent with stable wage and price inflation respectively. These deviations are caused by fluctuations in the exogenous stochastic disturbances of the model, and can be interpreted as supply shocks.

5 Although this choice of decision lag is somewhat arbitrary, it is no more arbitrary than choosing to specify our model at a quarterly frequency - or, for that matter, any frequency — in the absence of compelling evidence to the contrary. Instead, we could introduce and estimate a free parameter that captures the average decision lag of households due to, eg, time-to-build constraints. 
where the coefficient $\psi^{w} \equiv \gamma^{w} \lambda /\left(1-\gamma^{w}(1-\lambda)\right)$ equals 1 for $\gamma^{w}=1$, the case in which all wage adjustments are effective the following period. The variable $\nu_{t-1}$ is the revision from $t-2$ to $t-1$ in expectations of the long-term real interest rate in period $t$. Such revisions reduce wage inflation because they raise the returns households expect from their future earnings.

The same type of assumption is made for price setters, giving a modified relation for the determination of price inflation:

$$
\pi_{t}=\left(1-\psi^{p}\right) E_{t-2} \pi_{t}+\psi^{p}\left[\kappa^{p}\left(\hat{Y}_{t}-\hat{Y}_{t}^{p}\right)+\delta^{p} \hat{w}_{t}+\beta E_{t-1} \pi_{t+1}\right]
$$

where $\gamma^{p}$ is the fraction of firms who can apply a newly chosen price at the beginning of period $t$ and $\psi^{p} \equiv \gamma^{p} \alpha /\left(1-\gamma^{p}(1-\alpha)\right)$.

\subsection{Choice of parameter values}

The simulations of alternative policy rules that we perform in the next section require us to specify stochastic processes for the shocks and provide values of the model parameters. Here we utilise estimates obtained in Amato and Laubach (1999) because the model is identical. The parameter estimates are presented in Table 1. The results are based on quarterly US data on real GDP, the GDP deflator, compensation per hour and the federal funds rate from 1980:1 to 1997:3. Below we briefly discuss the values obtained for the parameters.

Table 1

\section{Structural parameters}

\begin{tabular}{|cc|cc|cc|}
\hline \multicolumn{2}{|c|}{ Preferences } & \multicolumn{2}{c|}{ Wage Inflation } & \multicolumn{2}{c|}{ Price Inflation } \\
\hline$\beta$ & $0.99 /$ quarter & $\lambda$ & $0.66 /$ quarter & $\alpha$ & $0.66 /$ quarter \\
$\sigma$ & 0.26 & $\gamma^{w}$ & 0.56 & $\gamma^{p}$ & 0.56 \\
& & $\kappa^{w}$ & 0.035 & $\kappa^{p}$ & 0.019 \\
& & $\delta^{w}$ & 0.066 & $\delta^{p}$ & 0.058 \\
\hline
\end{tabular}

The steady-state gross real rate of return in our model is $\beta^{-1}$, and since the average ex post real interest rate in the sample is one percent (on a quarterly basis), we set $\beta$ equal to 0.99 . The intertemporal elasticity of substitution $\sigma^{-1}$ is 3.9 , which is larger than what has been found in the non-durable consumption literature, but may be justified since consumption in our model proxies for all interestrate sensitive components of output. The parameters $\lambda$ and $\alpha$ are chosen such that wages and prices 
remain unchanged on average for 3 quarters, consistent with several survey studies. The values $\gamma^{w}$ and $\gamma^{p}$ are estimated to be 0.56 , which means that slightly more than half of newly chosen wages and prices are implemented in the next quarter. Given the other parameter values, our estimates for $\kappa^{w}$ and $\kappa^{p}$ are consistent with steady-state markups in labour and goods markets of $13 \%$ and $19 \%$ respectively. While we are not aware of any empirical evidence concerning the markup of real wages over the marginal rate of substitution between leisure and consumption, our estimate of the steady-state markup in goods markets is consistent with findings in other studies. Finally, the parameter $\delta^{p}$ reflects the estimate of $\kappa^{p}$ and an assumed labour share in income of $2 / 3$, while the parameter $\delta^{w}$ is consistent with the estimate of $\kappa^{w}$, a labour share of $2 / 3$, and an elasticity of households' disutility from labour supply of 5 .

\section{Alternative objectives for monetary policy}

The goal of this section is to characterise the behaviour of the economy under various objectives for monetary policy, and to evaluate the desirability of these objectives in terms of their welfare properties. The section starts by providing an approximation to the lifetime utility of the representative household, expressed in terms of a weighted sum of the variances of the endogenous variables. This approximation facilitates the evaluation of the welfare consequences of alternative policies. The second subsection presents what we call "forecast-based objectives" for monetary policy. The purpose is to formalise the notion that the central bank is instructed to minimise fluctuations in some goal variables that are forecastable $s$ periods ahead.

We then evaluate the welfare properties of various such objectives, and in particular the importance of the "policy horizon" $s$. Monetary policy is assumed to operate by using simple feedback rules for the short-term interest rate, eg Taylor-type rules, where the parameters in these rules are chosen to optimise the particular delegated objective under consideration. It has been argued that such simple rules are attractive because they enhance the transparency of monetary policy, which is complementary to considering forecast-based objectives as a means for simplifying the institutional structure of monetary policy. Our results using this approach are presented in the third subsection.

\subsection{Household welfare}

The criterion for evaluating alternative policies is the expected value of the representative household's welfare. In Appendix B, we show that this quantity can be approximated by

$$
W=-\Omega\left[L+\left(1+c_{2}\right) \bar{\pi}^{2}\right]
$$


where

$$
\begin{aligned}
L & =\operatorname{var}\left(\pi_{t}\right)+\left(\psi^{p^{-1}}-1\right) \operatorname{var}\left(\pi_{t}-E_{t-2} \pi_{t}\right)+c_{1} \operatorname{var}\left(E_{t-2}\left[\hat{Y}_{t}-\hat{Y}_{t}^{e}\right]\right) \\
& +c_{2}\left[\operatorname{var}\left(\pi_{t}^{w}\right)+\left(\psi^{w^{-1}}-1\right) \operatorname{var}\left(\pi_{t}^{w}-E_{t-2} \pi_{t}^{w}\right)\right]
\end{aligned}
$$

is the welfare loss associated with variability of the output gap and price and wage inflation, and $\Omega, c_{1}$ and $c_{2}$ are combinations of the model's parameters. The measure of potential output $\hat{Y}_{t}^{e}$, the Pareto-efficient level of output that would obtain under completely flexible prices and wages, is a convex combination of the values of output consistent with flexible prices $\left(\hat{Y}_{t}^{p}\right)$ and wages $\left(\hat{Y}_{t}^{w}\right)$.

The form of this loss function is similar to ad hoc objectives assumed in many studies of monetary policy design, and similar to the concern for output and inflation variability expressed in, eg, Taylor (1979). The coefficients $c_{1}$ and $c_{2}$ express the weights of output gap and wage inflation variability relative to price inflation variability in (8). For our parameter estimates, $c_{1}=0.13$ and $c_{2}=0.89$. The small value of $c_{1}$ implies that an increase in the variance of price inflation is roughly eight times as costly as an equivalent increase in the variance of the output gap.

The presence of the first moment $\bar{\pi}^{2}$ in (7) is due to the fact that even a constant, perfectly anticipated rate of inflation different from zero forces households and firms to adjust their wages and prices whenever they have the opportunity to do so. The implied dispersion of relative prices and wages is welfare reducing because at any point in time the condition that the real wage equal the desired markup over the marginal rate of substitution is violated for most households, and likewise the condition that price equal the desired markup over marginal cost is violated for most firms. The first moment term is important once it is taken into account that nominal interest rates cannot fall below zero in an economy where noninterest-bearing money is held. Suppose a given interest rate policy implies an unconditional standard deviation $\sigma(R)$ for the nominal interest rate, and that under such a policy all realisations of the interest rate are confined to an interval of size $k \sigma(R)$ on each side of the steady state value $\bar{R}$. For the zero lower bound on nominal interest rates to hold at all times, $\bar{R} \geq k \sigma(R)$ has to hold. Since $\bar{R}=\bar{\pi}+\rho$, ie the steady state nominal interest rate equals the steady state inflation rate plus the steady state real interest rate, we have that $\bar{\pi} \geq k \sigma(R)-\rho$. This last inequality shows that a more volatile interest rate policy can only be implemented at the cost of a higher steady state inflation rate, which reduces welfare. In the results reported below, we take this constraint into account by evaluating the objective

$$
W=-\Omega\left[L+\left(1+c_{2}\right)(\max \{k \sigma(R)-\rho, 0\})^{2}\right]
$$


The values of $k$ and $\rho$ are set to 2.46 and $3.04 \%$, respectively, which have been estimated using the US data from our previous work.

\subsection{Forecast-based objectives}

As discussed in the Introduction, the rationale for having policy decisions depend explicitly on forecasts may be sought either in the dynamic response of goal variables to interest rate changes, or in the argument that by stabilising forecasts for a subset of goal variables, the outcome may resemble the one in which policy aims at stabilising the realised values of all goal variables. To formalise the use of forecasts in policy decisions, we assume that the objective delegated to the central bank can be described by

$$
\min _{\left\{R_{t}\right\}} E\left[\left(E_{t} \pi_{t+s}-\bar{\pi}\right)^{2}+\chi_{1}\left(E_{t}\left[\hat{Y}_{t+s}-\hat{Y}_{t+s}^{e}\right]\right)^{2}+\chi_{2}\left(E_{t} \pi_{t+s}^{w}-\bar{\pi}\right)^{2}\right]
$$

This loss function penalises deviations of forecasts, ie conditional expectations, of goal variables from target. ${ }^{6}$ The outer (unconditional) expectation makes the optimal path of interest rates (eg the interest rate rule) independent of the state of the economy when it is chosen. It is instructive to rewrite the objective (10) as

$$
\min _{\left\{R_{t}\right\}} \operatorname{var}\left(E_{t} \pi_{t+s}\right)+\chi_{1} \operatorname{var}\left(E_{t}\left[\hat{Y}_{t+s}-\hat{Y}_{t+s}^{e}\right]\right)+\chi_{2} \operatorname{var}\left(E_{t} \pi_{t+s}^{w}\right)
$$

For the special case of (11) with $s=0$, the central bank is charged with minimising some combination of the unconditional variances of the goal variables. ${ }^{7}$ By increasing $s$, the central bank is instructed to stabilise only the component of fluctuations in the goal variables that is forecastable beyond a particular horizon. In respect of the zero lower bound for nominal interest rates, we append (11) to penalise excessive variation in $R_{t}$ (as in the previous subsection). The problem is thus to minimise

$$
\begin{aligned}
F B O(s)= & \operatorname{var}\left(E_{t} \pi_{t+s}\right)+\chi_{1} \operatorname{var}\left(E_{t}\left[\hat{Y}_{t+s}-\hat{Y}_{t+s}^{e}\right]\right) \\
& +\chi_{2} \operatorname{var}\left(E_{t} \pi_{t+s}^{w}\right)+\left(1+\chi_{2}\right)(\max \{k \sigma(R)-\rho, 0\})^{2}
\end{aligned}
$$

Inspection of the welfare loss (8) associated with variability of the output gap and wage and price inflation suggests that stabilising merely some forecastable component of fluctuations in the goal variables is not welfare improving. Not only are all fluctuations in all three endogenous variables welfare-reducing, fluctuations in wage and price inflation that are unforecastable two periods ahead are

$6 \quad$ The results reported below remain qualitatively unchanged when, instead of the forecast of the variables at some future point, the average of forecasted values over a number of quarters enters the objective. The latter may correspond more closely to the practice of focussing on forecasts of, say, annual inflation over the second year ahead.

7 It is important to note that the case with $\chi_{2}=0$ does not correspond to the case most commonly considered in the literature because the measure of the output gap in (11) has a different interpretation from what most authors use. The measure of output gap used in studies such as Taylor (1993) is exactly our variable $\hat{Y}$, the deviation of $\log$ output from its steady state. In our empirical work, we measure the steady state output level using a linear trend estimated over our sample. See Amato and Laubach (1999) for further discussion of this issue. 
particularly undesirable, as they cause additional distortions due to the particular specification of price setting considered in the model. Hence, the rationale that, due to lags in the transmission mechanism, monetary policy should aim at stabilising forecasts instead of actual values of goal variables is certainly not an implication of our model. This holds despite the fact that in our model monetary policy does have lagged effects on all the endogenous variables.

Suppose, however, that monetary policy is directed at stabilising only a subset of the variables entering the welfare objective (9), ie that in (12) either $\chi_{1}$ or $\chi_{2}$ or both equal 0 . The case of $\chi_{1}=\chi_{2}=0$, combined with an appropriate horizon, may for instance be viewed as a reasonable description of inflation targeting, as suggested by Goodhart (1998). As discussed in the introduction, delegation of such a restricted objective may be sensible if it increases the transparency and accountability of the central bank. Moreover, delegation of a less restricted objective involves specifying values for $\chi_{1}$ and $\chi_{2}$, agreement on which may be hard to reach. Under such a restricted objective, stabilising only those fluctuations of the variable(s) entering (12) that are forecastable at some horizon, instead of all fluctuations, may be welfare-improving according to the objective (9). This would be the case if fluctuations in the variables entering (12) that are forecastable beyond a particular horizon are more highly correlated with the weighted average of fluctuations in the endogenous variables entering (8) than are all fluctuations in the variables entering (12). In the next subsection, we report results for the cases in which either $\chi_{1}$, or $\chi_{2}$, or both are set to 0 .

\subsection{Results for simple rules}

Interest-rate rules that implement the optimal plan for some given objective are generally complicated. Rotemberg and Woodford (1999) show that, for their model, rules confined to a few terms closely approximate the welfare achieved by unrestricted optimal plans. Also, because simple rules are more transparent, they are more likely to be inferred by private agents, thereby increasing the chance that a committed policy will reap its benefits. The form of simple rule we use includes feedback from real wages and lagged interest rates:

$$
\hat{R}_{t}=a \hat{w}_{t}+b \pi_{t}+c \hat{Y}_{t}+d \hat{R}_{t-1}
$$

Tables 2 and 3 present results from simulating the model under various interest-rate rules, which have been obtained by minimising the objective (12) over the coefficients $a, b, c$ and $d$ in (13) for the horizons listed at the top of the table. In Table 2 we report results for the case in which $\chi_{1}=\chi_{2}=0$, while in Table 3 we consider results when either $\chi_{1}$ or $\chi_{2}$ is different from 0 . For comparison, the final two columns of Table 2 present results under the rule that minimises the welfare criterion (9), and under the 
historical rule estimated in our previous work. ${ }^{8}$ For each different objective, the table first presents the resulting coefficients for the interest-rate rule, followed by the unconditional variances of the model's endogenous variables, the level of steady-state inflation necessary to avoid the zero lower bound for nominal interest rates to be binding, and finally the value of the term inside brackets of the welfare criterion (9). The variances of wage and price inflation and the interest rate are expressed in annualised percentage points, while the variance of output and the output gap are measured in percentage deviations from trend.

Table 2

Minimization of forecast-based objectives: $\chi_{1}=\chi_{2}=0$

\begin{tabular}{||c|cccccccc||}
\hline Horizon & 1 & 4 & 5 & 8 & 12 & 16 & W & VAR \\
\hline$a$ & -0.04 & 0.11 & 0.13 & -0.02 & 0.00 & -0.20 & 0.25 & - \\
$b$ & 0.76 & 0.72 & 0.71 & 0.70 & 0.64 & 0.59 & 0.76 & - \\
$c$ & 0.03 & -0.03 & -0.02 & 0.01 & 0.00 & -0.02 & 0.02 & - \\
$d$ & 1.07 & 1.01 & 1.02 & 1.04 & 1.00 & 0.94 & 1.13 & - \\
$\operatorname{var}(\hat{R})$ & 1.57 & 1.55 & 1.55 & 1.55 & 1.55 & 1.54 & 1.56 & 6.14 \\
$\operatorname{var}(\pi)$ & 0.36 & 0.45 & 0.44 & 0.36 & 0.39 & 0.55 & 0.44 & 2.00 \\
$\operatorname{var}\left(\pi-E_{-2} \pi\right)$ & 0.21 & 0.25 & 0.25 & 0.22 & 0.23 & 0.22 & 0.24 & 0.43 \\
$\operatorname{var}\left(\pi^{w}\right)$ & 2.29 & 2.08 & 2.05 & 2.23 & 2.17 & 2.63 & 2.07 & 3.94 \\
$\operatorname{var}\left(\pi^{w}-E_{-2} \pi^{w}\right)$ & 1.74 & 1.54 & 1.52 & 1.71 & 1.69 & 2.02 & 1.45 & 2.02 \\
$\operatorname{var}(\hat{Y})$ & 10.94 & 15.23 & 14.81 & 11.65 & 12.87 & 14.63 & 12.07 & 4.12 \\
$\operatorname{var}\left(E_{-2}\left(\hat{Y}-\hat{Y}^{e}\right)\right)$ & 9.29 & 10.67 & 10.61 & 9.44 & 9.79 & 10.49 & 9.98 & 10.76 \\
$\bar{\pi}$ & 0.04 & 0.02 & 0.02 & 0.03 & 0.02 & 0.02 & 0.03 & 3.05 \\
$\mathrm{~W}$ & 5.66 & 5.57 & 5.52 & 5.61 & 5.62 & 6.62 & 5.37 & 26.89 \\
\hline
\end{tabular}

Care should be taken in interpreting the coefficients in the various interest-rate rules because their values are determined jointly so that monetary policy responds optimally to the given restricted set of state variables on the right-hand side of (13). However, it is interesting to note that the response to both the current real wage and current output is weak and in some cases negative. By contrast, the response to current inflation is strong under any of the rules. Finally, the coefficient on the lagged interest rate almost always exceeds 1 . Due to the link between interest rate variability and the steady-state level of inflation

\footnotetext{
8 In our previous work, we identified the historical policy rule with the interest rate equation from a VAR, allowing for contemporaneous feedback from the other endogenous variables.
} 
discussed in section 3.1, a commitment to highly persistent interest-rate changes is optimal, as argued by Woodford (1999b).

The high degree of interest rate inertia under all the simulated rules, and the fact that agents in our rational expectations model anticipate this degree of inertia, implies that all simulations are characterised by low (compared to historical standards) interest rate variability. Moreover, the small values of the steady-state inflation rate $\bar{\pi}$ induced by the interest-rate variability shown in the second to last line of Table 2 indicate that the welfare gains from further stabilisation that could be achieved by a more variable interest-rate policy are too small to warrant the concomitant increase in $\bar{\pi}$.

The variance of price inflation under all the objectives is only a small fraction of its historical value. This reflects the large weight given to inflation stabilisation under all the objectives, which is furthermore perfectly understood by agents. The variance of output is much larger under any of the simulated rules than under the historical one, while the same is not true for the output gap. Whereas in the model the only rationale for output stabilisation is stabilisation of output around its efficient level, such behaviour does not seem to characterise historical policy. This suggests that the process $\hat{Y}$ is more similar to policymakers' estimate of the output gap than the discrepancy between detrended output and the highly variable process of estimated disturbances to the efficient level of output $\hat{Y}^{e}$.

Significant differences in economic performance under the various objectives appear in the comparisons of the variances of price and wage inflation and the output gap. The most important feature is that for horizons up to 12 quarters, the variances of price inflation and the output gap are almost perfectly correlated, while the variance of wage inflation moves in the opposite direction. While the unconditional variances of price inflation and the output gap increase almost monotonically by moving from horizon 1 to horizon 5 , the unconditional variance of wage inflation is reduced sufficiently to more than offset the welfare loss from the increase in price and output gap variance. The variances obtained under the rule that minimises (9) also suggest that a slight increase in the variance of price inflation is necessary to achieve a substantial reduction in the variability of wage inflation. Among the various simulated rules reported in Table 2, the one minimising expected inflation 5 quarters ahead comes closest in terms of welfare to the one that is optimal under the objective (9). Minimising the unconditional variance of inflation (ie horizon 1) or the variance of expected inflation 4,8 or 12 quarters ahead generates only marginally higher welfare losses. By contrast, minimising the variance of expected inflation 16 quarters ahead leads to considerably higher welfare losses. 
Table 3

Minimization of forecast-based objectives: $\chi_{1}, \chi_{2} \neq 0$

\begin{tabular}{||c|cccc|cccc||}
\hline & \multicolumn{4}{|c|}{$\chi_{1}=c_{1}, \chi_{2}=0$} & \multicolumn{4}{c||}{$\chi_{1}=0, \chi_{2}=c_{2}$} \\
\hline Horizon & 1 & 4 & 8 & 12 & 1 & 4 & 8 & 12 \\
\hline$a$ & -0.03 & 0.10 & 0.09 & 0.05 & 0.13 & 0.01 & 0.15 & -0.01 \\
$b$ & 0.79 & 0.69 & 0.63 & 0.64 & 0.58 & 0.53 & 0.50 & 0.53 \\
$c$ & 0.04 & -0.02 & -0.03 & -0.03 & 0.00 & -0.03 & -0.07 & -0.04 \\
$d$ & 1.09 & 1.01 & 0.98 & 0.98 & 1.02 & 0.94 & 0.92 & 0.92 \\
$\operatorname{var}(\hat{R})$ & 1.60 & 1.55 & 1.54 & 1.55 & 1.53 & 1.53 & 1.55 & 1.54 \\
$\operatorname{var}(\pi)$ & 0.36 & 0.43 & 0.47 & 0.46 & 0.44 & 0.53 & 1.10 & 0.61 \\
$\operatorname{var}\left(\pi-E_{-2} \pi\right)$ & 0.21 & 0.25 & 0.26 & 0.26 & 0.26 & 0.27 & 0.39 & 0.28 \\
$\operatorname{var}\left(\pi^{w}\right)$ & 2.31 & 2.06 & 2.05 & 2.10 & 2.01 & 2.16 & 2.39 & 2.25 \\
$\operatorname{var}\left(\pi^{w}-E_{-2} \pi^{w}\right)$ & 1.73 & 1.55 & 1.54 & 1.61 & 1.51 & 1.68 & 1.42 & 1.72 \\
$\operatorname{var}(\hat{Y})$ & 10.43 & 14.50 & 15.66 & 15.52 & 13.11 & 16.64 & 29.29 & 18.36 \\
$\operatorname{var}\left(E_{-2}\left(\hat{Y}-\hat{Y}^{e}\right)\right)$ & 9.23 & 10.45 & 11.00 & 10.76 & 10.36 & 11.36 & 19.11 & 12.04 \\
$\bar{\pi}$ & 0.07 & 0.02 & 0.02 & 0.02 & 0.01 & 0.00 & 0.02 & 0.01 \\
$\mathrm{~W}$ & 5.67 & 5.53 & 5.63 & 5.70 & 5.45 & 5.98 & 7.61 & 6.28 \\
\hline
\end{tabular}

The first four columns in Table 3 report results for the case in which the coefficient $\chi_{1}$ is set to $c_{1}$, the weight on the output gap term in the welfare objective (9), and $\chi_{2}=0$. Compared to the results presented in Table 2, the variance of wage inflation is higher for the shortest horizon, the case in which the unconditional variances enter the objective (12), but lower for the remaining three horizons. By contrast, the variances of price inflation and, interestingly, the output gap, are lower at horizons 1 and 4 when the output gap term is included in (12), but higher at the remaining horizons. Hence, charging the central bank with output gap stabilisation seems to have the desired effect only if the central bank is charged with minimising the variability of all fluctuations in the goal variables, and not just those forecastable at a horizon longer than one year. In terms of welfare, the tradeoffs among the variances of the various goal variables as the horizon changes lead to the lowest welfare loss for horizon 4 , but affords only a slight reduction in welfare losses compared to the case without output gap stabilisation entering (12). Increasing $\chi_{1}$ to values larger than $c_{1}$ leads initially to marginal improvements in welfare, but soon thereafter welfare is reduced compared to $\chi_{1}=0$.

The last four columns in Table 3 consider the case in which $\chi_{1}=0$ and $\chi_{2}$ is set equal to the coefficient $c_{2}$ in (9). In this case, stabilisation of all fluctuations in wage and price inflation leads to a sizeable 
reduction in the variance of wage inflation, as one might expect, compared to the case of $\chi_{2}=0$, while the variances of price inflation and the output gap increase moderately. Of all the cases considered in Tables 2 and 3, this one yields the closest approximation in terms of welfare to the welfare-optimal rule displayed in Table 2, despite the fact that the coefficients in the two interest rate rules are quite different. By contrast, stabilising only those fluctuations in price and wage inflation that are forecastable 4 quarters or more ahead leads to much higher variances of the output gap and price and wage inflation compared to the case of $\chi_{2}=0$. The component of a weighted average of price and wage inflation that is forecastable 4 or more quarters ahead is apparently not nearly as closely correlated with the combination of variables entering the welfare objective than is either current price and wage inflation, or price inflation that is forecastable 4 or 5 quarters ahead.

\section{Conclusions}

This article has studied the welfare consequences of delegating to the central bank the task of minimising fluctuations in a subset of the model's endogenous variables that are forecastable at some horizon. Studying the implications of these delegated objectives is motivated by the observation that a number of central banks operate under directives which are not necessarily intended to reflect society's preferences over various goal variables. When the objective delegated to the central bank penalises fluctuations in only a subset of the variables that the public cares about, it can be welfare-improving to require that the central bank stabilise only fluctuations in this subset of variables that are forecastable at some horizon, as opposed to fluctuations at all frequencies. The rationale for this use of forecasts is that the forecastable components of the subset of variables may be more highly correlated with all fluctuations in the entire set of variables that society cares about. Based on our model determining price and wage inflation and output, we find that if an objective defined solely in terms of price inflation variability is delegated to the central bank, the requirement that only the fluctuations forecastable 5 quarters ahead should be stabilised is welfare-improving. However, if the objective delegated to the central bank may be specified over the variability of more than one goal variable, the best alternative to delegating the welfare objective (9) directly is to delegate the minimisation of the unconditional variances of both wage and price inflation. In this case, stabilising merely forecastable fluctuations in these two variables leads to significant welfare losses. 


\section{A. The structural model}

In this appendix, we derive the equations of the model introduced in section 2.

\section{A.1 Setup}

The economy consists of a continuum of households and firms, and there is a continuum of differentiated, perishable goods and differentiated kinds of labour services. Each household is the monopolistic supplier of one kind of labour service, and consumes a CES aggregate of all the differentiated goods. The household sets a nominal wage for its labour services, and supplies as many hours as are demanded at its chosen wage. Each firm is the monopolistic producer for one good, and uses a CES aggregate of households' labour services in the production process. The firm sets a price for its good, and satisfies demand at this price. Because the analysis focusses on the effects of monetary policy at the business cycle horizon, capital accumulation is not modelled.

Households Household $i$ 's utility is defined over the index $C_{t}^{i}$, where

$$
C_{t}^{i}=\left[\int_{0}^{1} c_{t}^{i}(z)^{\frac{\theta-1}{\theta}} d z\right]^{\frac{\theta}{\theta-1}}
$$

$z$ denotes a specific good, and $\theta>1$ parameterises the elasticity of substitution in the household's preferences between the various goods. As $\theta$ gets large, goods become ever closer substitutes, whereas if $\theta$ approaches 1 from above, goods are less and less substitutable. Hence $\theta$ also measures the market power of each of the firms located on the interval $[0,1]$, with market power decreasing in $\theta$.

The "consumption-based price index" is defined as

$$
P_{t} \equiv\left[\int_{0}^{1} p_{t}(z)^{1-\theta} d z\right]^{\frac{1}{1-\theta}}
$$

The price index $P_{t}$ denotes the minimum amount the household has to spend to obtain one unit of the composite good $C_{t}$ defined as in (14). Maximising the index (14) for a given level of consumption expenditure, the household allocates consumption across individual products according to

$$
c_{t}^{i}(z)=\left[\frac{p_{t}(z)}{P_{t}}\right]^{-\theta} C_{t}^{i}
$$

Household $i$ is the sole supplier of labour services $h^{i}$, and its objective is to maximise

$$
E_{0}\left[\sum_{t=0}^{\infty} \beta^{t}\left(u\left(C_{t}^{i} ; \xi_{t}\right)-v\left(h_{t}^{i} ; \zeta_{t}\right)\right)\right]
$$


subject to a demand schedule for its labour services and the budget constraint

$$
E_{t}\left[\delta_{t, t+1} A_{t+1}^{i}\right] \leq A_{t}^{i}+W_{t}^{i} h_{t}^{i}+\Pi_{t}-P_{t} C_{t}^{i}
$$

Within each period, the household derives utility $u\left(\cdot ; \xi_{t}\right)$ from consumption $C_{t}^{i}$ as defined in (14), while supplying hours $h_{t}^{i}$ reduces utility, as indicated by the function $v\left(\cdot ; \zeta_{t}\right)$. In the budget constraint, $P_{t}$ denotes the price index defined in (15), and $A_{t}$ denotes the nominal value of the household's holdings of financial assets at the beginning of period $t . W_{t}^{i}$ is the hourly wage that household $i$ charges, and $\Pi_{t}$ the household's share in firms' profits, which we assume are distributed lump-sum to households. $\delta_{t, \tau}$ is a stochastic discount factor, pricing in period $t$ assets whose payoffs are in period $\tau$. Financial markets are assumed to be complete, and in particular there exists a riskless one-period nominal bond, the gross return on which is given by $R_{t} \equiv\left(E_{t} \delta_{t, t+1}\right)^{-1}$. The stochastic disturbances $\xi_{t}$ and $\zeta_{t}$ affect the household's utility from consumption and disutility from labour supply, respectively. The household's choice variables are consumption and hours or, given the demand function for its labour services, its wage.

Firms Firm $z$ is the monopolistic supplier of $\operatorname{good} z$, which it produces according to the production function

$$
y_{t}(z)=e^{\eta_{t}} \bar{K}^{a} H_{t}(z)^{1-a}
$$

where $\eta_{t}$ denotes a stochastic technology disturbance, the capital stock employed by each firm is fixed at $\bar{K}$, and the firm's labour input is a CES aggregate of different households' labour services

$$
H_{t}(z)=\left[\int_{0}^{1} h_{t}^{i}(z)^{\frac{\phi-1}{\phi}} d i\right]^{\frac{\phi}{\phi-1}}
$$

The parameter $\phi>1$ characterises the elasticity of substitution between the various types of labour services. The wage index $W_{t}$ is defined as

$$
W_{t} \equiv\left[\int_{0}^{1}\left(W_{t}^{i}\right)^{1-\phi} d i\right]^{\frac{1}{1-\phi}}
$$

Maximising the index (20) for a given level of wage payments, firm $z$ allocates demand for individual labour services according to

$$
h_{t}^{i}(z)=\left[\frac{W_{t}^{i}}{W_{t}}\right]^{-\phi} H_{t}(z)
$$

Aggregate demand for output is defined as $Y_{t}=C_{t}+G_{t}$, where $C_{t} \equiv \int_{0}^{1} C_{t}^{i} d i$, and $G_{t}$ is an exogenously given component of demand for output, which is assumed to be determined one period ahead. Assuming that $G_{t}$ is allocated across the different goods by maximising an index defined analogous to the consumption index (14), the demand faced by firm $z$ is given by

$$
y_{t}(z)=\left[\frac{p_{t}(z)}{P_{t}}\right]^{-\theta} Y_{t}
$$


Analogously, by integrating (22) across firms, the demand for its labour services faced by household $i$ is

$$
h_{t}^{i}=\left[\frac{W_{t}^{i}}{W_{t}}\right]^{-\phi} H_{t}
$$

where $H_{t} \equiv \int_{0}^{1} H_{t}(z) d z$.

\section{A.2 Approximation of first-order conditions}

We now characterise households' utility-maximising consumption and wage decisions, and firms' profitmaximising price choices. Because we wish to use solution methods for linear rational expectations models, the equilibrium conditions we use are log-linear approximations to the exact, nonlinear first order conditions of households and firms. For reasons discussed in Woodford (1999a) the welfare analysis later on is facilitated by log-linearising around the efficient steady state, ie the steady state corresponding to a situation without market power and nominal rigidities in goods and labour markets. The efficient steady state level of output is determined by the condition that households' marginal rate of substitution between labour and consumption equal marginal product of labour, ie

$$
\frac{v_{h}(H(\bar{Y}) ; 0)}{u_{c}(\bar{Y}-\bar{G} ; 0)}=(1-a)(\bar{Y} / \bar{K})^{-\frac{a}{1-a}}
$$

where $\bar{Y}$ and $\bar{G}$ denote the steady state values of output and exogenous demand respectively. The presence of market power of households and firms implies that, absent some offsetting policy, the steady state output level is below this efficient level of output. To justify log-linearising the exact equilibrium conditions around the efficient steady state, below we will have to assume that tax policies are in place which offset the inefficiencies caused by imperfect competition in goods and labour markets. Furthermore, we log-linearise around a steady state in which there is zero price and wage inflation.

"IS equation" Households are assumed to choose their consumption purchases two periods ahead, ie $C_{t}^{i}$ is chosen in $t-2$. The decision lag for consumption implies that the household's Euler equation takes the form

$$
E_{t} u_{c}\left(C_{t+2}^{i} ; \xi_{t+2}\right)=E_{t} \lambda_{t+2}^{i} P_{t+2}
$$

where $\lambda_{t}^{i}$ denotes household $i$ 's marginal utility of income at date $t$. Since households are free to take investment decisions each period with immediate effect, $\lambda_{t}$ has to satisfy

$$
\lambda_{t}=\beta E_{t}\left[R_{t} \lambda_{t+1}\right]
$$

Dropping the superscript $i$ implicitly assumes that, because of complete markets, households insure themselves against all idiosyncratic risk, and therefore the path of consumption is identical across households. Let $\hat{\lambda}_{t}$ denote the percentage deviation of $\lambda_{t} P_{t}$ from its steady state value. Then the log- 
linear approximation of (27) is

$$
\begin{aligned}
\hat{\lambda}_{t} & =E_{t}\left[\hat{R}_{t}-\pi_{t+1}+\hat{\lambda}_{t+1}\right] \\
& =\sum_{T=t}^{\infty} E_{t}\left[\hat{R}_{T}-\pi_{T+1}\right]
\end{aligned}
$$

where $\hat{R}_{t}$ is the percentage deviation of the interest rate from its steady state value consistent with zero inflation. The log-linear approximation of the Euler equation (26) is therefore

$$
-\tilde{\sigma} E_{t}\left[\hat{C}_{t+2}-\tilde{\xi}_{t+2}\right]=\sum_{T=t+2}^{\infty} E_{t}\left[\hat{R}_{T}-\pi_{T+1}\right]
$$

where $\hat{C}_{t} \equiv\left(C_{t}-\bar{C}\right) / \bar{C}$ denotes the percentage deviation of consumption from its steady state value $\bar{C}, \tilde{\sigma} \equiv-u_{c c}(\bar{C}) \bar{C} / u_{c}(\bar{C})$, and $\tilde{\xi}_{t} \equiv-\left(u_{c \xi}(\bar{C}) / u_{c c}(\bar{C}) \bar{C}\right) \xi_{t}$ is the disturbance to the marginal utility of consumption.

Log-linearising aggregate demand around the steady state yields

$$
\hat{Y}_{t}=s_{c} \hat{C}_{t}+\tilde{G}_{t}
$$

where $\hat{Y}_{t} \equiv\left(Y_{t}-\bar{Y}\right) / \bar{Y}, \tilde{G}_{t} \equiv\left(G_{t}-\bar{G}\right) / \bar{Y}$, and $s_{c} \equiv \bar{C} / \bar{Y}$. By substituting from the log-linearised aggregate demand equation for $C_{t}$, the Euler equation can be written as

$$
\hat{Y}_{t}=-\sigma^{-1} E_{t-2} \sum_{T=t}^{\infty}\left[\hat{R}_{T}-\pi_{T+1}\right]+\hat{G}_{t}
$$

where $\sigma \equiv \tilde{\sigma} / s_{c} \equiv-u_{c c}(\bar{C}) \bar{Y} / u_{c}(\bar{C})$, and $\hat{G}_{t} \equiv \tilde{G}_{t}+s_{c} E_{t-2} \tilde{\xi}_{t}$. Equation (32) is the model's "IS equation" and is identical to equation (4) in the main text.

Wage inflation The assumption for wage and price adjustment we use is Rotemberg and Woodford's (1997) variant of Calvo's (1983) staggered price setting. Each period a fraction $1-\lambda$ of households is chosen at random and independent of their individual histories, and is being offered the opportunity to set a new wage. Rotemberg and Woodford assume furthermore that at the end of period $t-1$, a fraction $\gamma^{w}$ of those households who choose a new wage can apply this wage beginning at date $t$, the remaining fraction $1-\gamma^{w}$ applies this wage beginning at date $t+1$. Let $W_{t}^{1}$ denote the wage chosen in $t-1$ by those households whose wage comes into effect in period $t$, and let $W_{t}^{2}$ denote the wage chosen in $t-2$ by those households whose wage comes into effect in $t$. The aggregate wage level is then given by

$$
W_{t}=\left[\lambda W_{t-1}^{1-\phi}+(1-\lambda) \gamma^{w}\left(W_{t}^{1}\right)^{1-\phi}+(1-\lambda)\left(1-\gamma^{w}\right)\left(W_{t}^{2}\right)^{1-\phi}\right]^{\frac{1}{1-\phi}}
$$

The wage $W_{t}^{1}$ is chosen to maximise

$$
E_{t-1} \sum_{T=t}^{\infty}(\lambda \beta)^{T-t}\left[\lambda_{T}\left(1+\tau_{w}\right) W_{t}^{1}\left(\frac{W_{t}^{1}}{W_{T}}\right)^{-\phi} H_{T}-v\left(\left(\frac{W_{t}^{1}}{W_{T}}\right)^{-\phi} H_{T} ; \zeta_{T}\right)\right]
$$


Since the wage chosen at the end of period $t-1$ will apply at time $t$ with probability 1 , at time $t+1$ with probability $\lambda$ and so forth, the household discounts utility in future periods conditional on $W_{t}^{1}$ still applying by $(\lambda \beta)^{T-t}$. Marginal utility of income at any point in time is the same across households. Therefore, the household's utility from charging wage $W_{t}^{1}$ in period $T$ is given by the product of marginal utility of income and earnings (the first term in brackets) less the disutility from supplying $\left(W_{t}^{1} / W_{T}\right)^{-\phi} H_{T}$, the number of hours demanded at wage $W_{t}^{1}$ and aggregate wages and hours $W_{T}$ and $H_{T}$ (the second term in brackets). $\tau_{w}$ denotes a subsidy for employment. By choosing $\tau_{w}=(\phi-1)^{-1}$, the effect of imperfect competition in labour markets on the steady state output level can be offset.

The first-order condition for $W_{t}^{1}$ can be expressed as

(35) $E_{t-1} \sum_{T=t}^{\infty}(\lambda \beta)^{T-t}\left(\frac{W_{t}^{1}}{W_{T}}\right)^{-\phi} H_{T}\left[v_{h}\left(\left(\frac{W_{t}^{1}}{W_{T}}\right)^{-\phi} H_{T} ; \zeta_{T}\right)-\frac{\phi-1}{\phi} \lambda_{T} P_{T}\left(1+\tau_{w}\right) \frac{W_{t}^{1}}{P_{T}}\right]=0$

Households choose their nominal wage in period $t-1$ such that the discounted sum of expected future real wages $\left(1+\tau_{w}\right) W_{t}^{1} / P_{T}$ equals the discounted sum of expected future marginal rates of substitution between consumption and leisure $v_{h}\left(h_{\mathbb{T} T}^{1} ; \zeta_{T}\right) /\left(\lambda_{T} P_{T}\right)$ times a markup $\frac{\phi}{\phi-1}$, where we used $h_{t T}^{1}$ as shorthand for the number of hours supplied in period $T$ at wage $W_{t}^{1}$.

Let $\hat{v}_{t}^{1} \equiv \log \left(W_{t}^{1} / W_{t}\right)$. The ratio $W_{t}^{1} / W_{T}$ can then be approximated as $\hat{v}_{t}^{1}-\sum_{k=1}^{T-t} \pi_{t+k}^{w}$. Similarly, the ratio

$$
\frac{W_{t}^{1}}{P_{T}}=\frac{W_{t}^{1}}{W_{t}} \frac{W_{t}}{P_{t}} \frac{P_{t}}{P_{T}}
$$

is approximated by $\hat{v}_{t}^{1}+\hat{w}_{t}-\sum_{k=1}^{T-t} \pi_{t+k}$, where $\hat{w}_{t} \equiv \log \left(W_{t} / P_{t}\right)$ denotes the percentage deviation of the real wage from its steady state. Finally, using the production function (19), the deviation of hours from steady state can be expressed as $\hat{H}_{t}=\frac{1}{1-a}\left(\hat{Y}_{t}-\eta_{t}\right)$.

With this notation, the log-linear approximation of (35) can be written as

$$
E_{t-1} \sum_{T=t}^{\infty}(\lambda \beta)^{T-t}\left\{\omega\left[\frac{\hat{Y}_{T}-\eta_{T}}{1-a}-\tilde{\zeta}_{T}-\phi\left(\hat{v}_{t}^{1}-\sum_{k=1}^{T-t} \pi_{t+k}^{w}\right)\right]-\hat{\lambda}_{T}-\left(\hat{v}_{t}^{1}+\hat{w}_{t}-\sum_{k=1}^{T-t} \pi_{t+k}\right)\right\}=0
$$

where $\omega \equiv v_{h h}(\bar{H} ; 0) \bar{H} / v_{h}(\bar{H} ; 0)$ measures the elasticity of the disutility of labour supply at the steady state level of hours $\bar{H}$ and $\tilde{\zeta}_{t} \equiv-\left(v_{h \zeta}(\bar{H} ; 0) / v_{h h}(\bar{H} ; 0) \bar{H}\right) \zeta_{t}$ is the disturbance to the marginal disutility of labour supply. Combining (29) and (32) yields

$$
E_{t-1} \hat{\lambda}_{T}=-\sigma E_{t-1}\left[\hat{Y}_{T}-\hat{G}_{T}\right] \forall T \geq t+1
$$

while taking expectations as of $t-1$ of (28) yields

$$
\begin{aligned}
E_{t-1} \hat{\lambda}_{t} & =E_{t-1}\left[\hat{R}_{t}-\pi_{t+1}+\hat{\lambda}_{t+1}\right] \\
& =E_{t-1}\left[\hat{R}_{t}-\pi_{t+1}-\sigma\left(\hat{Y}_{t+1}-\hat{G}_{t+1}\right)\right]
\end{aligned}
$$




$$
=-\sigma E_{t-1}\left[\hat{Y}_{t}-\hat{G}_{t}\right]+\nu_{t-1}
$$

where

$$
\begin{aligned}
\nu_{t-1} & \equiv E_{t-1}\left[R_{t}-\pi_{t+1}-\sigma\left(\hat{Y}_{t+1}-\hat{Y}_{t}-\hat{G}_{t+1}+\hat{G}_{t}\right)\right] \\
& =E_{t-1} \sum_{T=t}^{\infty}\left(\hat{R}_{T}-\pi_{T+1}\right)-E_{t-2} \sum_{T=t}^{\infty}\left(\hat{R}_{T}-\pi_{T+1}\right)
\end{aligned}
$$

Substituting these expressions for $E_{t-1} \hat{\lambda}_{T}$ into (36) and collecting terms, (36) can be written as

$$
\begin{array}{r}
E_{t-1} \sum_{T=t}^{\infty}(\lambda \beta)^{T-t}\left\{\left(\frac{\omega}{1-a}+\sigma\right) \hat{Y}_{T}-\frac{\omega}{1-a} \eta_{T}-\omega \tilde{\zeta}_{T}-\sigma \hat{G}_{T}\right. \\
\left.\left.-(1+\omega \phi) \hat{v}_{t}^{1}+\omega \phi \sum_{k=1}^{T-t} \pi_{t+k}^{w}-\hat{w}_{t}+\sum_{k=1}^{T-t} \pi_{t+k}\right)\right\}-\nu_{t-1}=0
\end{array}
$$

Furthermore, we transform the double summation

$$
\begin{aligned}
\sum_{T=t}^{\infty}(\lambda \beta)^{T-t} \sum_{k=1}^{T-t} \pi_{t+k} & =\sum_{T=t+1}^{\infty}(\lambda \beta)^{T-t} \sum_{k=0}^{\infty}(\lambda \beta)^{k} \pi_{T} \\
& =(1-\lambda \beta)^{-1}\left(\sum_{T=t}^{\infty}(\lambda \beta)^{T-t} \pi_{T}-\pi_{t}\right)
\end{aligned}
$$

The double sum involving $\pi_{t}^{w}$ is transformed analogously.

We next wish to obtain an expression for $\hat{v}_{t}^{1}$ in terms of $\pi_{t}^{w}$. Dividing both sides of (33) by $W_{t}$ and taking the logarithm yields

$$
0 \simeq(1-\lambda) \gamma^{w} \hat{v}_{t}^{1}+(1-\lambda)\left(1-\gamma^{w}\right) \hat{v}_{t}^{2}-\lambda \pi_{t}^{w}
$$

Since $W_{t}^{2}=E_{t-2} W_{t}^{1}$,

$$
\hat{v}_{t}^{2}=E_{t-2} \hat{v}_{t}^{1}-\left(\pi_{t}^{w}-E_{t-2} \pi_{t}^{w}\right)
$$

Substituting this expression into (40) we obtain

$$
\pi_{t}^{w}=\frac{1-\lambda}{\lambda}\left[\gamma^{w} \hat{v}_{t}^{1}+\left(1-\gamma^{w}\right)\left(E_{t-2} \hat{v}_{t}^{1}-\left(\pi_{t}^{w}-E_{t-2} \pi_{t}^{w}\right)\right)\right]
$$

Taking expectations as of $t-2$ on both sides, $E_{t-2} \pi_{t}^{w}=\frac{1-\lambda}{\lambda} E_{t-2} \hat{v}_{t}^{1}$ and hence

$$
\frac{1-\lambda}{\lambda} \hat{v}_{t}^{1}=\frac{1}{\psi^{w}} \pi_{t}^{w}-\frac{1-\psi^{w}}{\psi_{w}} E_{t-2} \pi_{t}^{w}
$$

where $\psi^{w}$ is defined in the main text.

Substitute (43) for $\hat{v}_{t}^{1}$ in (39) and use the transformation for the double sums and the fact that $E_{t-1} \nu_{t+j}=0 \forall j \geq 0$; derive the corresponding relation for $W_{t}^{2}$; and, use the log-linear approximation of the wage index (33). Combining we obtain the following law of motion for the rate of wage inflation $\pi_{t}^{w} \equiv \log \left(W_{t} / W_{t-1}\right):$

(44) $\pi_{t}^{w}=\left(1-\psi^{w}\right) E_{t-2} \pi_{t}^{w}+\psi^{w}\left[\kappa^{w}\left(\hat{Y}_{t}-\hat{Y}_{t}^{w}\right)-\frac{\kappa^{w}(1-a)}{\omega+\sigma(1-a)}\left(\hat{w}_{t}+\nu_{t-1}\right)+\beta E_{t-1} \pi_{t+1}^{w}\right]$ 
where the coefficient

$$
\kappa^{w} \equiv \frac{(1-\lambda)(1-\lambda \beta)}{\lambda} \frac{\omega+\sigma(1-a)}{(1+\phi \omega)(1-a)}
$$

describes the elasticity of wage inflation with respect to the gap between actual output $\hat{Y}_{t}$ and

$$
\hat{Y}_{t}^{w} \equiv \frac{1-a}{\omega+\sigma(1-a)} E_{t-1}\left[\frac{\omega}{1-a} \eta_{t}+\omega \tilde{\zeta}_{t}+\sigma \hat{G}_{t}\right]
$$

the level of output consistent with stable wage inflation. This is equation (5) in the main text, where $\delta^{w} \equiv \frac{\kappa^{w}(1-a)}{\omega+\sigma(1-a)}$.

Price inflation Price adjustment by firms is modelled analogous to wage adjustment by households. Each period a fraction $1-\alpha$ of firms is chosen at random and independent of their individual histories, and is being offered the opportunity to adjust their price. At the end of period $t-1$, a fraction $\gamma^{p}$ of those who choose a new price can apply this price beginning at date $t$, the remaining fraction $1-\gamma^{p}$ applies this price beginning at date $t+1$. Let $p_{t}^{1}$ denote the price chosen in $t-1$ by those firms whose price comes into effect in period $t$, and let $p_{t}^{2}$ denote the price chosen in $t-2$ by those firms whose price comes into effect in $t$. The aggregate price level is then given by

$$
P_{t}=\left[\alpha P_{t-1}^{1-\theta}+(1-\alpha) \gamma^{p}\left(p_{t}^{1}\right)^{1-\theta}+(1-\alpha)\left(1-\gamma^{p}\right)\left(p_{t}^{2}\right)^{1-\theta}\right]^{\frac{1}{1-\theta}}
$$

The price $p_{t}^{1}$ is chosen to maximise

$$
E_{t-1} \sum_{T=t}^{\infty} \alpha^{T-t} \delta_{t, T}\left[\left(1+\tau_{p}\right) p_{t}^{1}\left(\frac{p_{t}^{1}}{P_{T}}\right)^{-\theta} Y_{T}-W_{T}\left(\left(\frac{p_{t}^{1}}{P_{T}}\right)^{-\theta} \frac{Y_{T}}{e^{\eta_{T}}}\right)^{\frac{1}{1-a}}\right]
$$

Since the price chosen at the end of period $t-1$ will apply at time $t$ with probability 1 , at time $t+1$ with probability $\alpha$ and so forth, the firm discounts future profits conditional on $p_{t}^{1}$ still applying by $\alpha^{T-t} \delta_{t, T}$, where $\delta_{t, T}$ is the stochastic discount factor introduced in (18). The first term in brackets denotes revenues in period $T$ at price $p_{t}^{1}$, the second term the firm's labour cost implied by the level of output that is demanded in period $T$ at price $p_{t}^{1} . \tau_{p}$ denotes a subsidy for producing output. By choosing $\tau_{p}=(\theta-1)^{-1}$, the effect of imperfect competition in goods markets on the steady state output level can be offset.

The first-order condition with respect to $p_{t}^{1}$ can be written as

$$
\begin{aligned}
E_{t-1} & \sum_{T=t}^{\infty} \alpha^{T-t} \delta_{t, T}\left(\frac{p_{t}^{1}}{P_{T}}\right)^{-\theta} Y_{T} \\
\cdot & {\left[\left(1+\tau_{p}\right) p_{t}^{1}-\frac{\theta}{\theta-1}(1-a)^{-1} e^{\frac{-\eta_{T}}{1-a}} W_{T}\left(\left(\frac{p_{t}^{1}}{P_{T}}\right)^{-\theta} Y_{T}\right)^{\frac{a}{1-a}}\right]=0 }
\end{aligned}
$$

Firms set the price in period $t-1$ such that the price, adjusted for the subsidy, equals a weighted average of expected future marginal cost at the level of output demanded at price $p_{t}^{1}$, times a markup $\frac{\theta}{\theta-1}$. 
A log-linear approximation to this first-order condition involves the same steps used above. Using this $\log$-linear approximation, as well as the corresponding relation for $p_{t}^{2}$ and the log-linear approximation of the price index (46), we obtain equation (6) in the main text, given by

$$
\pi_{t}=\left(1-\psi^{p}\right) E_{t-2} \pi_{t}+\psi^{p}\left[\kappa^{p}\left(\hat{Y}_{t}-\hat{Y}_{t}^{p}\right)+\frac{\kappa^{p}(1-a)}{a} \hat{w}_{t}+\beta E_{t-1} \pi_{t+1}\right]
$$

where $\delta^{p} \equiv \frac{\kappa^{p}(1-a)}{a}, \kappa^{p} \equiv(1-\alpha)(1-\alpha \beta) a /(\alpha(1-a+\theta a)), \hat{Y}_{t}^{p} \equiv a^{-1} E_{t-1} \eta_{t}$ is the level of output consistent with stable price inflation and $\psi^{p}$ is defined in the main text.

To summarise, the model consists of the IS equation (32), the wage inflation equation (44) and the price inflation equation (49). Except for stochastic disturbances, wage and price inflation are predetermined one period ahead, output two periods ahead. The structural disturbances of the model are $\hat{G}_{t}, \hat{Y}_{t}^{w}$ and $\hat{Y}_{t}^{p}$. Accounting for these shocks, which are predetermined one period ahead, makes wage and price inflation and output also predetermined one period ahead. The model parameters are $\beta, \sigma, \omega, a, \alpha, \theta, \gamma^{p}, \lambda, \phi$ and $\gamma^{w}$. In addition to the parameter values reported in Table $1, a$ is set to 0.25 , and $\omega$ is estimated to be 0.2 . The value for $a$, together with the steady-state markup in goods markets of $19 \%$ implied by our estimate of $\kappa^{p}$, implies a labour share of $63 \%$. The estimates of $\kappa^{w}$ and $\kappa^{p}$ reported in Table 1 imply $\phi=8.48$ and $\theta=6.27$. 


\section{B. Approximation of household welfare}

In this appendix, we derive the second-order approximation (7) to the unconditional expectation of the representative household's welfare, which is given by

$$
W=E\left[u\left(C_{t} ; \xi_{t}\right)-\int_{0}^{1} v\left(h_{t}^{i} ; \zeta_{t}\right) d i\right]
$$

Specifically, we form a second-order Taylor series expansion of (50) around the steady state characterised by the efficient output level $\bar{Y}$ defined in (25) and zero wage and price inflation. Hence, we form the approximation around the same steady state around which the model's exact equilibrium conditions have been log-linearised.

Since the demand side of our model is identical to Rotemberg and Woodford's, the second-order approximation of $u\left(C_{t} ; \xi_{t}\right)$ is identical to their equation (9.10) as well, which we reproduce here:

$$
u\left(C_{t} ; \xi_{t}\right)=u_{c} \bar{Y} \hat{Y}_{t}+\frac{1}{2}\left(u_{c} \bar{Y}+u_{c c} \bar{Y}^{2}\right) \hat{Y}_{t}^{2}-u_{c c} \bar{Y}^{2} \hat{G}_{t} \hat{Y}_{t}+u n f+t i p+\mathcal{O}\left(\|\xi\|^{3}\right)
$$

where $u n f$ stands for terms that are unforecastable two periods ahead (since in our model monetary policy affects output only with a lag of two periods), and tip denotes terms that are independent of monetary policy. $\|\xi\|$ is a bound on the amplitude of fluctuations in the exogenous disturbances, which we take to be the same for $\xi, \zeta$, and $\eta$. The term $\mathcal{O}\left(\|\xi\|^{3}\right)$ indicates that terms of third or higher order in the deviations of the various variables from their steady-state values are being neglected.

Similarly, a second-order approximation of household $i$ 's disutility of labour supply is given by

$$
v\left(h_{t}^{i} ; \zeta_{t}\right)=v_{h} \bar{H} \hat{h}_{t}^{i}+\frac{1}{2}\left(v_{h} \bar{H}+v_{h h} \bar{H}^{2}\right) \hat{h}_{t}^{i 2}-v_{h h} \bar{H}^{2} \tilde{\zeta}_{t} \hat{h}_{t}^{i}+t i p+\mathcal{O}\left(\|\xi\|^{3}\right)
$$

where $\hat{h}_{t}^{i} \equiv \log \left(h_{t}^{i} / \bar{H}\right)$. Integrating (52) over $i$ yields

$$
\begin{aligned}
& \int_{0}^{1} v\left(h_{t}^{i} ; \zeta_{t}\right) d i=v_{h} \bar{H} E_{i}\left[\hat{h}_{t}^{i}\right] \\
& \quad+\frac{1}{2}\left(v_{h} \bar{H}+v_{h h} \bar{H}^{2}\right)\left(E_{i}\left[\hat{h}_{t}^{i}\right]^{2}+\operatorname{var}_{i}\left(\hat{h}_{t}^{i}\right)\right)-v_{h h} \bar{H}^{2} \tilde{\zeta}_{t} E_{i}\left[\hat{h}_{t}^{i}\right]+\operatorname{tip}+\mathcal{O}\left(\|\xi\|^{3}\right)
\end{aligned}
$$

By integrating (20) over $z$, we obtain

$$
H_{t}=\left[\int_{0}^{1}\left(h_{t}^{i}\right)^{\frac{\phi-1}{\phi}} d i\right]^{\frac{\phi}{\phi-1}}
$$

Using (54) and the fact that for a random variable $X, \log E[X]=E[\log X]+\frac{1}{2} \operatorname{var}(\log X)+\mathcal{O}\left(\|X\|^{3}\right)$, we obtain that

$$
\hat{H}_{t} \equiv \log \left(H_{t} / \bar{H}\right)=E_{i}\left[\hat{h}_{t}^{i}\right]+\frac{\phi-1}{2 \phi} \operatorname{var}_{i}\left(\hat{h}_{t}^{i}\right)
$$

Solving (55) for $E_{i}\left[\hat{h}_{t}^{i}\right]$ and substituting in (53) yields

$$
\int_{0}^{1} v\left(h_{t}^{i} ; \zeta_{t}\right) d i=v_{h} \bar{H} \hat{H}_{t}+\frac{v_{h} \bar{H}}{2}(1+\omega) \hat{H}_{t}^{2}
$$




$$
+\frac{v_{h} \bar{H}}{2}\left(\phi^{-1}+\omega\right) \operatorname{var}_{i}\left(\hat{h}_{t}^{i}\right)-v_{h h} \bar{H}^{2} \tilde{\zeta}_{t} \hat{H}_{t}+t i p+\mathcal{O}\left(\|\xi\|^{3}\right)
$$

where $\omega$ is defined as in (44).

We next wish to substitute for $\hat{H}_{t}$ in (56) in terms of output. To do so, note first that the definition of $H_{t}=\int_{0}^{1} H_{t}(z) d z$ implies that

$$
\hat{H}_{t}=E_{z}\left[\hat{H}_{t}(z)\right]+\frac{1}{2} \operatorname{var}_{z}\left(\hat{H}_{t}(z)\right)
$$

Firms' production function in turn implies that

$$
E_{z}\left[\hat{H}_{t}(z)\right]=(1-a)^{-1}\left(E_{z}\left[\hat{y}_{t}(z)\right]-\eta_{t}\right), \operatorname{var}_{z}\left(\hat{H}_{t}(z)\right)=(1-a)^{-2} \operatorname{var}_{z}\left(\hat{y}_{t}(z)\right)
$$

and therefore

$$
\hat{H}_{t}=(1-a)^{-1}\left(E_{z}\left[\hat{y}_{t}(z)\right]-\eta_{t}\right)+\frac{1}{2(1-a)^{2}} \operatorname{var}_{z}\left(\hat{y}_{t}(z)\right)
$$

Finally, deriving an expression for $\hat{Y}_{t}$ analogous to (57), substituting from this expression for $E_{z}\left[\hat{y}_{t}(z)\right]$ in (59), and substituting the resulting expression for $\hat{H}_{t}$ into (56) yields

$$
\begin{gathered}
\int_{0}^{1} v\left(h_{t}^{i} ; \zeta_{t}\right) d i=\frac{v_{h} \bar{H}}{1-a}\left[\hat{Y}_{t}+\frac{1+\omega}{2(1-a)} \hat{Y}_{t}^{2}\right]-\frac{v_{h} \bar{H}}{1-a}\left[\omega \tilde{\zeta}_{t} \hat{Y}_{t}+\frac{1+\omega}{1-a} \eta_{t} \hat{Y}_{t}\right] \\
\text { (60) }+\frac{v_{h} \bar{H}}{1-a}\left[\frac{1}{2}\left(\frac{1}{1-a}-\frac{\theta-1}{\theta}\right) \operatorname{var}_{z}\left(\hat{y}_{t}(z)\right)+\frac{1-a}{2}\left(\phi^{-1}+\omega\right) \operatorname{var}_{i}\left(\hat{h}_{t}^{i}\right)\right]+\operatorname{tip}+\mathcal{O}\left(\|\xi\|^{3}\right)
\end{gathered}
$$

Because the efficient steady-state level of output is characterised by (25), it follows that

$$
\frac{v_{h} \bar{H}}{1-a}=u_{c} \bar{Y}
$$

Hence,

$$
\begin{aligned}
& u\left(C_{t} ; \xi_{t}\right)-\int_{0}^{1} v\left(h_{t}^{i} ; \zeta_{t}\right) d i=u_{c} \bar{Y}\left[\frac{\omega+a+\sigma(1-a)}{1-a}\left(\hat{Y}_{t} \hat{Y}_{t}^{e}-\frac{1}{2} \hat{Y}_{t}^{2}\right)\right. \\
& \left.-\frac{1}{2}\left(\frac{1}{1-a}-\frac{\theta-1}{\theta}\right) \operatorname{var}_{z}\left(\hat{y}_{t}(z)\right)-\frac{1-a}{2}\left(\phi^{-1}+\omega\right) \operatorname{var}_{i}\left(\hat{h}_{t}^{i}\right)\right]+\operatorname{tip}+\mathcal{O}\left(\|\xi\|^{3}\right)
\end{aligned}
$$

where

$$
\hat{Y}_{t}^{e} \equiv \frac{\omega+\sigma(1-a)}{\omega+a+\sigma(1-a)} \hat{Y}_{t}^{w}+\left(1-\frac{\omega+\sigma(1-a)}{\omega+a+\sigma(1-a)}\right) \hat{Y}_{t}^{p}
$$

is the efficient level of output that would obtain if prices and wages were flexible. Taking the unconditional expectation of (61) then leads to an expression for (50) of the form

$$
\begin{aligned}
W= & -\frac{u_{c} \bar{Y}}{2}\left[\frac{\omega+a+\sigma(1-a)}{1-a}\left(E\left[\hat{Y}_{t}^{2}\right]-2 E\left[\hat{Y}_{t} \hat{Y}_{t}^{e}\right]\right)\right. \\
& \left.+\left(\frac{1}{1-a}-\frac{\theta-1}{\theta}\right) E\left[\operatorname{var}_{z}\left(\hat{y}_{t}(z)\right)\right]+(1-a)\left(\phi^{-1}+\omega\right) E\left[\operatorname{var}_{i}\left(\hat{h}_{t}^{i}\right)\right]\right]+t i p+\mathcal{O}\left(\|\xi\|^{3}\right)
\end{aligned}
$$


We now wish to substitute for each of the three terms involving unconditional expectations in (63). First, rearranging the definition of $\operatorname{var}\left(\hat{Y}_{t}-\hat{Y}_{t}^{e}\right)$ yields

$$
E\left[\hat{Y}_{t}^{2}\right]-2 E\left[\hat{Y}_{t} \hat{Y}_{t}^{e}\right]=\operatorname{var}\left(\hat{Y}_{t}-\hat{Y}_{t}^{e}\right)+E\left[\hat{Y}_{t}\right]^{2}-E\left[\hat{Y}_{t}^{e 2}\right]+E\left[\hat{Y}_{t}^{e}\right]^{2}-2 E\left[\hat{Y}_{t}\right] E\left[\hat{Y}_{t}^{e}\right]
$$

The second and last terms on the right-hand side of (64) are zero because the unconditional expectation of detrended output is zero by definition. The sum of the third and fourth terms equals $-\operatorname{var}\left(\hat{Y}_{t}^{e}\right)$, a term that is independent of policy. Hence, in (63) we can substitute $\operatorname{var}\left(\hat{Y}_{t}-\hat{Y}_{t}^{e}\right)$ for the left-hand side of (64). Taking account of the fact that interest rates affect output only with two periods lag, we instead substitute $\operatorname{var}\left(E_{t-2}\left[\hat{Y}_{t}-\hat{Y}_{t}^{e}\right]\right)$ in (63).

Second, from the demand functions for households' labour services (22) and producers' goods (23) it follows that

$$
E\left[\operatorname{var}_{i}\left(\hat{h}_{t}^{i}\right)\right]=\phi^{2} E\left[\operatorname{var}_{i}\left(\log W_{t}^{i}\right)\right]
$$

and

$$
E\left[\operatorname{var}_{z}\left(\hat{y}_{t}(z)\right)\right]=\theta^{2} E\left[\operatorname{var}_{z}\left(\log p_{t}(z)\right)\right]
$$

Following the argument in Rotemberg and Woodford's Appendix 3, these equations can be rewritten as

$$
E\left[\operatorname{var}_{i}\left(\hat{h}_{t}^{i}\right)\right]=\phi^{2} \frac{\lambda}{(1-\lambda)^{2}}\left[\operatorname{var}\left(\pi_{t}^{w}\right)+\left(\psi^{w^{-1}}-1\right) \operatorname{var}\left(\pi_{t}^{w}-E_{t-2} \pi_{t}^{w}\right)+\left(E \pi_{t}^{w}\right)^{2}\right]
$$

and

$$
E\left[\operatorname{var}_{z}\left(\hat{y}_{t}(z)\right)\right]=\theta^{2} \frac{\alpha}{(1-\alpha)^{2}}\left[\operatorname{var}\left(\pi_{t}\right)+\left(\psi^{p^{-1}}-1\right) \operatorname{var}\left(\pi_{t}-E_{t-2} \pi_{t}\right)+\left(E \pi_{t}\right)^{2}\right]
$$

where $\psi^{w}$ and $\psi^{p}$ are defined as in (44) and (49) respectively. Substituting (64), (67), and (68) into (63), and noting that

and

$$
(1-a)\left(\phi^{-1}+\omega\right) \phi^{2} \frac{\lambda}{(1-\lambda)^{2}}=\frac{1-\lambda \beta}{1-\lambda} \frac{\phi(\omega+\sigma(1-a))}{\kappa^{w}}
$$

we obtain (7), where

$$
\left(\frac{1}{1-a}-\frac{\theta-1}{\theta}\right) \theta^{2} \frac{\alpha}{(1-\alpha)^{2}}=\frac{1-\alpha \beta}{1-\alpha} \frac{\theta a}{\kappa^{p}(1-a)}
$$

and

$$
\begin{gathered}
\Omega \equiv \frac{u_{c} \bar{Y}}{2} \frac{1-\alpha \beta}{1-\alpha} \frac{\theta a}{\kappa^{p}(1-a)} \\
c_{1} \equiv\left[\frac{1-\alpha \beta}{1-\alpha} \frac{\theta a}{\kappa^{p}(1-a)}\right]^{-1} \frac{\omega+a+\sigma(1-a)}{1-a}
\end{gathered}
$$

$$
c_{2} \equiv\left[\frac{1-\alpha \beta}{1-\alpha} \frac{\theta a}{\kappa^{p}(1-a)}\right]^{-1} \frac{1-\lambda \beta}{1-\lambda} \frac{\phi(\omega+\sigma(1-a))}{\kappa^{w}}
$$




\section{References}

Amato, Jeffery D and Thomas Laubach (1999): "Monetary Policy in an Estimated Optimization-Based

Model with Sticky Prices and Wages”. Manuscript, Bank for International Settlements.

Batini, Nicoletta and Andrew G Haldane (1999): "Forward-looking Rules for Monetary Policy”, in John B Taylor (ed), Monetary Policy Rules, NBER and Chicago University Press.

Batini, Nicoletta and Edward Nelson (2000): “Optimal Horizons for Inflation Targeting”. Bank of England Working Paper No 119.

Bernanke, Ben S and Michael Woodford (1997): "Inflation Forecasts and Monetary Policy". Journal of Money, Credit, and Banking 29, pp 653-84.

Calvo, Guillermo A (1983): "Staggered Prices in a Utility-Maximising Framework". Journal of Monetary Economics 12, pp 383-98.

Clarida, Richard, Jordi Galí and Mark Gertler (1998): "Monetary Policy Rules and Macroeconomic Stability: Evidence and Some Theory". NBER Working Paper No 6442.

Erceg, Christopher J (1997): "Nominal Wage Rigidities and the Propagation of Monetary Disturbances". Board of Governors International Finance Discussion Paper No 590.

Erceg, Christopher J, Dale W Henderson and Andrew T Levin (2000): “Optimal Monetary Policy with Staggered Wage and Price Conrtracts". Journal of Monetary Economics, forthcoming.

Goodhart, Charles A E (1998): "Central Bankers and Uncertainty". Keynes Lecture delivered at the British Academy, 29 October 1998. Reprinted in Bank of England Quarterly Bulletin February 1999, pp $102-14$.

Levin, Andrew T, Volker Wieland and John C Williams (1999): “The Performance of Forecast-Based Monetary Policy Rules under Model Uncertainty". Manuscript, Board of Governors of the Federal Reserve System.

McCallum, Bennett Tand Edward Nelson (1999): “An Optimizing IS-LM Specification for Monetary Policy and Business Cycle Analysis”. Journal of Money, Credit, and Banking 31, pp 296-316.

Rogoff, Kenneth (1985): “The Optimal Degree of Commitment to an Intermediate Monetary Target". Quarterly Journal of Economics 100, pp 1169-89. 
Roberts, John M (1995): "New Keynesian Economics and the Phillips Curve". Journal of Money, Credit, and Banking 27, pp 975-84.

Rotemberg, Julio J and Michael Woodford (1997): “An Optimisation-Based Econometric Framework for the Evaluation of Monetary Policy", in Ben S Bernanke and Julio J Rotemberg (eds), NBER Macroeconomics Annual, pp 297-346. Expanded version circulated as NBER Technical Working Paper No 233, 1998.

Rotemberg, Julio J and Michael Woodford (1999): "Interest-Rate Rules in an Estimated Sticky Price Model”, in John B Taylor (ed), Monetary Policy Rules, NBER and Chicago University Press.

Smets, Frank (2000): “What Horizon for Price Stability?" European Central Bank Working Paper No 24.

Svensson, Lars E O (1997): "Inflation Forecast Targeting: Implementing and Monitoring Inflation Targets". European Economic Review 41, pp 1111-1146.

Svensson, Lars E O and Michael Woodford (1999): "Implementing Optimal Policy through InflationForecast Targeting". Manuscript, Princeton University.

Taylor, John B (1979): "Estimation and Control of a Macroeconomic Model with Rational Expectations". Econometrica 47, pp 1267-1286.

Taylor, John B (1993): "Discretion Versus Policy Rules in Practice". Carnegie-Rochester Conference Series on Public Policy 39, pp 195-214.

Woodford, Michael (1999a): "Inflation Stabilisation and Welfare". Manuscript, Ch. 6 in Interest and Prices, Princeton University.

Woodford, Michael (1999b): “Optimal Monetary Policy Inertia”. NBER Working Paper No 7261. 




\section{Recent BIS Working Papers}

No Title Author

73

August 1999

74

August 1999

75

August 1999

76

October 1999

77

October 1999

78

October 1999

79

November 1999

80

November 1999

81

November 1999

82

November 1999

83

January 2000

84

January 2000

85

January 2000

86

March 2000

87

May 2000

88

June 2000
The Taylor rule and interest rates in the EMU area: a note

The dollar-mark axis

A note on the Gordon growth model with nonstationary dividend growth

The price of risk at year-end: evidence from interbank lending

Perceived central bank intervention and market expectations: an empirical study of the yen/dollar exchange rate, 1993-96

Banking and commerce: a liquidity approach

Pass-through of exchange rates and import prices to domestic inflation in some industrialised economies

A note on alternative measures of real bond rates

Interbank interest rates and the risk premium

Sacrifice ratios and the conduct of monetary policy in conditions of low inflation

Switching from single to multiple bank lending relationships: determinants and implications

What have we learned from recent financial crises and policy responses?

A defence of the expectations theory as a model of US long-term interest rates

Information, liquidity and risk in the international interbank market: implicit guarantees and private credit market failure

Monetary policy in an estimated optimisation-based model with sticky prices and wages

Evidence on the response of US banks to changes in capital requirements
Stefan Gerlach and

Gert Schnabel

Gabriele Galati

Henri Pagès

Craig H Furfine

Gabriele Galati and William Melick

Joseph G Haubrich and João A C Santos

Jonathan McCarthy

Palle S Andersen

Henri Pagès

Palle S Andersen and William L Wascher

Luísa A Farinha and João A C Santos

William R White

Gregory D Sutton

Henri Bernard and Joseph Bisignano

Jeffery D Amato and Thomas Laubach

Craig Furfine 


ISSN 1020-0959 